\title{
Short Bowel Syndrome and Food Aversion: The Role of "Messy Play" Therapy in Paediatric Patients
}

\author{
Laura Balance ${ }^{1}$, Riccardo Coletta ${ }^{2,3,4}$, Bashar Aldeiri ${ }^{2,4}$, Tracy Warburton $^{5}$, Angela Davies ${ }^{5}$, and Antonino \\ Morabito ${ }^{2,3,4 *}$ \\ ${ }^{1}$ School of Medicine, University of Manchester, United Kingdom \\ ${ }^{2}$ Division of Cell Matrix Biology and Regenerative Medicine, University of Manchester, United Kingdom \\ ${ }^{3}$ School of Environment and Life Science, University of Salford, United Kingdom \\ ${ }^{4}$ Paediatric Autologous Bowel Reconstruction and Rehabilitation Unit, Royal Manchester Children's Hospital, United Kingdom \\ ${ }^{5}$ Department of Therapeutic and Specialized Play, Royal Manchester Children's Hospital, United Kingdom
}

Submission: November 21, 2016; Published: December 01, 2016

"Corresponding author: Antonino Morabito, Consultant Paediatric and Neonatal Surgeon, Children's Hospital, M13 9WL, United Kingdom, Tel: 01617012194; E-mail: antonino.morabito@cmft.nhs.uk

\begin{abstract}
Short bowel syndrome (SBS) in children causes long-term complications. Food aversion (FA) is found in 25\% of patients with SBS, and contributes to growth and developmental delay. The aim of this study is to identify factors of SBS that cause FA and evaluate the outcome of using play specialist led feeding programmes. Ten patients with SBS and FA were enrolled into "messy play" therapy program, after which all patients were able to feed orally. An intensive structured programme centered on "our senses" and "messy play" appeared to increase oral intake and to be successful in children having FA.
\end{abstract}

Keywords: Pediatric; Intestinal failure; Intestinal rehabilitation unit; Short bowel syndrome

\section{Introduction}

Short Bowel Syndrome (SBS) refers to the malabsorption of fluids, nutrients and electrolytes seen following extensive bowel resection [1]. Malabsorption results in a plethora of symptoms, including diarrhea, dehydration, fatigue and failure to thrive. Although early initiation of some oral feeding has been shown to stimulate mucosal and muscular bowel adaptation, many children are initially exclusively tube fed. Prolonged tube feeding can lead to feeding aversion (FA) when weaning is attempted. Children affected by SBS are a unique group of patients, which represent a complex challenge for professionals and parents alike. A multidisciplinary nutrition support team is required in the managemen $[2,3]$. The present study tries to identify potential causative factors of FA and review the outcome of our play specialist led structured program.

\section{Material and Methods}

\section{Program overview}

The Therapeutic and Specialized Play team at Manchester Children Hospital applied "messy play" to the therapy sessions for 30 minutes, 2-3 times, weekly. "Messy play" approach aims to promote tolerance to different textures and tolerance to the feeding environment. The sessions ended with a reward system as positive reinforcement. These sessions begin with basic painting sessions, progressing to engaging in unprepared foods and ending with touching and handling, prepared foods.

\section{Participants}

Patients with SBS who developed FA were identified over a five-year period. FA was classified as one or more of the following symptoms: refusal of food; retching or vomiting at the presence of food or taste of food. 
Length of stay (LOS) in hospital, surgical procedures undergone, gastrostomy tube (GT) or Nasogastric tube (NG) feeding; duration of Parenteral Nutrition (PN) and life threatening problems (i.e. sepsis), were also evaluated as part of the aetiology of FA.

\section{Therapeutic and specialized play team approach}

The interventions within the program included:

Establishing relationship with feeder: Carer/Parent focused interventions were used (Table 1). They were shown how important their involvement is in the development of the child's feeding behaviour.

Table 1: Parent Focused Interventions.

\begin{tabular}{|c|}
\hline Dietary advice about the type of food offered. \\
\hline $\begin{array}{c}\text { Cognitive restructuring of parents' expectation of the child's } \\
\text { capabilities. }\end{array}$ \\
\hline $\begin{array}{c}\text { Behavioural management training to help parents to manage their } \\
\text { child's disruptive behaviour at mealtimes. }\end{array}$ \\
\hline $\begin{array}{c}\text { Training in strategies to avoid negative emotional association } \\
\text { with eating. }\end{array}$ \\
\hline pupporting parents to develop parenting skills to enhance \\
parents' sense of competence.
\end{tabular}

Assessing readiness for oral feeding: The included children were all biologically ready for a weaning plan and no future surgeries were scheduled electively. The child should have the essential oral-motor skills for their age and have gained enough weight for any subsequent weight loss in case the interventions do not work [4].

Normalizing feeding: The feeding plan began with oral desensitization. In this a child adapts to a new object that is viewed as a threat in the following order: sight, sound, smell, touch and then taste. Working through desensitization with controlled exposure helps to overcome previous learned responses. Escape preventions such as "flooding" (non removal of a stimulus such as a spoon) was used in 23 out of 38 studies in literature to overcome negative associations with sight of food. With flooding the child increases their acceptance of food while any negative behaviour is ignored by the feeder [5]. Texture desensitization was achieved by stroking the children's face starting at the cheeks and ears, moving slowly to the mouth and finally the tongue. This should be repeated several times a day, ideally by the caregiver, to promote bonding, interaction and communication [6].

Behavioral feeding plan: Behavioral programs are put in place to minimise any serious behavioral complexes. [4] A variety of behavioral techniques were applied, as outlined in the literature [7].

A. Positive reinforcement - Delivery of a desired stimulus that is contingent on the occurrence of a predetermined behaviour. E.g. Delivery of preferred food or something the child enjoys along with social praise.B. Modeling - Observation of another person performing the goal behaviour, e.g. Observation of the positive effects of the eating experience on others.

The programme was continued at home, making parental involvement vital.

\section{Measures of efficacy}

Quantitative assessment of outcome involved serial height and weight measurements, a food diary, developmental and feeding history and psychometric evaluation. Carers completed a Behavioral Paediatric Feeding Assessment Scale (BPFAS) [8].

\section{Results}

Ten patients $(17 \%$ Male) were identified. Age at diagnosis ranged between 14 months and 36. All patients in the series were tube fed (TF) since birth or soon after birth. Three patients had a gastrostomy tube (GT); all had a central line (CL) for PN. The children initially display behaviours of aversion but this lessened over the sessions. Demographic data are shown in Table 2. The exact time on tube feeding and therapy was not clear in 2 children.

Table 2: Participant demographics.

\begin{tabular}{|c|c|c|c|c|c|c|}
\hline & Medical Diagnosis & $\begin{array}{c}\text { Time Without Oral } \\
\text { Feed } \\
\text { (months) }\end{array}$ & Method of Feed & $\begin{array}{c}\text { Duration of } \\
\text { Parenteral } \\
\text { Nutrition }\end{array}$ & $\begin{array}{c}\text { Duration of } \\
\text { Treatment } \\
\text { (months) }\end{array}$ & $\begin{array}{c}\text { Duration of } \\
\text { Inpatient Stay } \\
\text { (Months) }\end{array}$ \\
\hline 1 & $\begin{array}{c}\text { Necrotizing } \\
\text { enterocolitis }\end{array}$ & 10 & Gastrostomy & since birth & 10 & 11 \\
\hline 2 & Gastroschisis & 8 & Nasogastric tube & since birth & 6 & 10 \\
\hline 3 & Gastroschisis & 10 & Nasogastric tube & since birth & 4 & 12 \\
\hline 4 & Gastroschisis & Exact time unclear & Gastrostomy & since birth & Exact time unclear & 6 \\
\hline 5 & Antenatal volvulus & Exact time unclear & Nasogastric tube & since birth & Exact time unclear & 8 \\
\hline 6 & Gastroschisis & 36 & Gastrostomy & since birth & 12 & 12 \\
\hline 7 & Gastroschisis & 14 & Gastrostomy & since birth & 10 & 8 \\
\hline 8 & Necrotizing & 8 & Nasogastric tube & since birth & 8 & 6 \\
\hline
\end{tabular}




\section{Advanced Research in Gastroenterology \& Hepatology}

\begin{tabular}{|c|c|c|c|c|c|c|}
\hline 9 & $\begin{array}{c}\text { Small Bowel } \\
\text { Atresia }\end{array}$ & 6 & Nasogastric tube & since birth & 2 & 4 \\
\hline 10 & $\begin{array}{c}\text { Necrotizing } \\
\text { enterocolitis }\end{array}$ & 12 & Nasogastric tube & since birth & 4 & 7 \\
\hline
\end{tabular}

At the beginning of therapy all 10 cases in this series demonstrated sensitization, later becoming engaged with weaning from TF and finally showing no inhibition to oral feeds. "Messy play" and our associated approach to FA were successful, due to positive reinforcement after successful food behaviour; this was done with a reward system, incorporation and education of the carers and most importantly encouraging the children to interact with food. After a median of 7 months of an intensive structured programme of "messy play" and behavioural therapy, $100 \%$ of patients were weaned off tube feeding and fed exclusively orally.

\section{Discussion}

Short bowel syndrome influences all aspects of a child's normal feeding routine. Parents and carers are encouraged to progress to oral feeding as early as possible, in order to stimulate the swallowing mechanism and enhance bowel adaptation as part of an Intestinal Rehabilitation Programme. Some patients referred to us were exclusively tube fed and demonstrated the phenomenon of food aversion, as a consequence of "negative association" with food. From our research several factors have been implicated in the development of food aversion in SBS patients.

During the first 6 months of life, a child's oral cavity develops and adapts for feeding: the oral cavity enlarges and tongue movements change to allow for solid foods [6]. At this time of adaptation the child is normally introduced to different textures of food. This exposure aids 'oral desensitization'. If this critical period is missed aberrant feeding habits emerge [9].

Primary carers of infants with SBS have been shown to feel most interaction when feeding the child. This daily routine allows physical proximity and develops a psychological bond. If the infant is tube fed from birth this emotional bond cannot develop [6]. Tube feeding is initially given continuously, to saturate the carrier proteins within the gut, maximize the absorptive gut surface area, and reduce vomiting [8]. However as continuous feeding is not physiological, children do not learn to link feeding with hunger and satiety [7]. The introduction of a naso-gastric tube can be distressing to paediatric patients causing irritation vomiting, and pain. This association between the discomfort of NG tubes and feeding becomes a negative conditioned response. As feeding is often stopped due to emesis and gagging, the child learns to push food away and retch to stop feeding. This learned response develops into food aversion [5]. Once established, these factors lead to feeding difficulties and consequentially cause short and long term physiological and psychological problems. A key success noted is when children at the same texture food at home as in the therapy session. Finally the environment must be normalized, since it is vital for the child to be relaxed and not anxious.

In the UK, the programme for weaning children from $\mathrm{TF}$ and $\mathrm{PN}$, involves decreasing the relative volume of $\mathrm{TF}$ or the duration of tube feed. To our knowledge, the UK NHS does not currently offer any intervention if a child displays aversion when weaning. This makes it very difficult to obtain any reliable epidemiological data $[10,11]$. This small case series was done to provisionally evaluate the therapy we used. Follow up of these 10 patients over several years, as well as prospectively evaluating a larger cohort of children may provide further evidence to support our conclusion.

\section{Conclusion}

This study shows that messy play approach associated with other supportive measures is successful in the resolution of FA related on SBS. This article stimulates the discussion on the value of "messy play" and regarding its role as an intervention, or even prevention, to food aversion. More awareness is needed about FA in SBS to guarantee progress. Preventing the development of FA should be the first goal of all those involved in the care of children affected by SBS.

\section{References}

1. Coletta R, Khalil BA, Morabito A (2014) Short bowel syndrome in children: surgical and medical perspectives. Semin Pediatr Surg 23(5): 291-297.

2. Barclay AR, Beattie LM, Weaver LT, Wilson DC (2011) Systematic review: medical and nutritional interventions for the management of intestinal failure and its resultant complications in children. Aliment Pharmacol Ther 33(2):1 75-184.

3. Khalil BA, Ba'ath ME, Aziz A, Forsythe L, Gozzini S, et al. (2012) Intestinal rehabilitation and bowel reconstructive surgery: improved outcomes in children with short bowel syndrome. J Pediatr Gastroenterol Nutr 54(4): 505-509.

4. Schauster H, Dwyer J (1996) Transition from tube feedings to feedings by mouth in children: preventing eating dysfunction. J Am Diet Assoc 96(3): 277-281.

5. Martin C, Southall A, Shea E, Marr A (2008) The Importance of a Multifaceted Approach in the Assessment and Treatment of Childhood Feeding Disorders A Two-Year-Old In-Patient Case Study in the U.K. National Health Service. Clinical Case Studies 7(2): 79-99.

6. Jadcherla SR, Stoner E, Gupta A, Bates DG, Fernandez S, et al. (2009) Evaluation and management of neonatal dysphagia: impact of pharyngoesophageal motility studies and multidisciplinary feeding strategy. J Pediatr Gastroenterol Nutr 48(2): 186-192.

7. Williams KE, Field DG, Seiverling L (2010) Food refusal in children: a review of the literature. Res Dev Disabil 31(3): 625-633.

8. Dovey MT, Isherwood E, Aldridge VK, Martin IC (2010) Typology of Feeding Disorders Based on a Single Assessment System Formulation of a Clinical Decision-Making Model. Childhood Obesity and Nutrition 2(1): 45-51. 
9. Mc Comish C, Brackett K, Kelly M, Hall C, Wallace S, et al. (2016) Interdisciplinary Feeding Team: A Medical, Motor, Behavioral Approach to Complex Pediatric Feeding Problems. MCN Am J Matern Child Nurs 41(4): 230-236.

10. Olieman JF, Penning C, Ijsselstijn H, Escher JC, Joosten KF, Hulst JM, et al. (2010) Enteral nutrition in children with short-bowel syndrome: current evidence and recommendations for the clinician. J Am Diet Assoc 110(3): 420-426

11. Silverman AH, Kirby M, Clifford LM, Fischer E, Berlin KS, Rudolph CD, et al. (2013) Nutritional and psychosocial outcomes of gastrostomy tube-dependent children completing an intensive inpatient behavioral treatment program. J Pediatr Gastroenterol Nutr 57(5): 668-672. 